
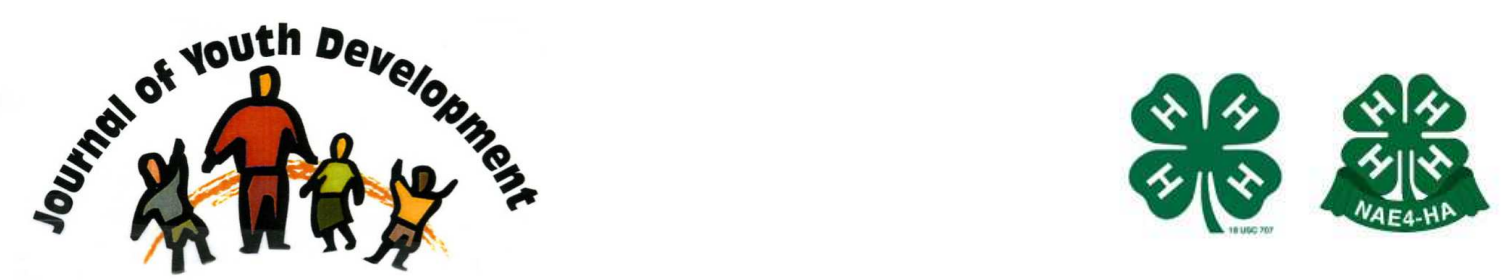

Bridging Research \& Practice

\title{
An Introduction to the SMARTRISK Heroes Program: Positive Social Marketing for Adolescent Injury Prevention
}

Philip R. Groff, Ph.D.

Director, Research \& Evaluation, SMARTRISK

pgroff@smartrisk.ca

Michael P. Shea, Ph.D. SMARTRISK Evaluation Coordinator

Robert Conn, MD, FRCSC CEO SMARTRISK 


\title{
JOURNAL OF YOUTH DEVELOPMENT \\ bridging research and practice

\section{An Introduction to the SMARTRISK Heroes Program: Positive Social Marketing for Adolescent Injury Prevention}

Philip R. Groff, Michael P. Shea and Robert Conn SMARTRISK

\begin{abstract}
This article provides background on the SMARTRISK Heroes Program, a mobile stage production that introduces young people to the prevalence of unintentional injury for their age group and presents them with a series of strategies that will reduce the likelihood that they will be unintentionally injured or killed. The program logic is consistent with theoretical work from the area of health promotion including the Protection Motivation Theory and the Transtheoretical Model of Stages of Change. The SMARTRISK Heroes Program has been the subject of a number of past evaluations that are briefly described. The program logic model was included in this article.
\end{abstract}




\section{Introduction}

\section{Background}

Every year in North America, more adolescents die from injury than all other causes of death combined (Statistics Canada, 2005; CDC, 2005a). The most prevalent unintentional injuries for adolescents are motor vehicle crashes, pedestrian and bicycle injuries, falls, sports-related injuries, drownings, and poisonings (CDC, 2005b). These unintentional injuries take more lives than cancer, meningitis, and all other causes of death combined. The vast majority of these unintentional injuries are both predictable and preventable, and yet adolescents continue to sustain long-term disabilities due to injuries. The following article will present a brief description of the SMARTRISK Heroes Program, a traveling injury prevention initiative that intends to increase the knowledge of high school students in the areas of injury prevention and risk management and to change their attitudes and behaviors in ways that will reduce the likelihood of their unintentional injury or death.

The SMARTRISK Heroes Program is a '... mobile stage production whose primary objective is to introduce young people to the notion of smart risk taking behaviors and empower them to make simple decisions that will significantly reduce their risk of injury' (SMARTRISK, 2000). The program consists of an hour-long presentation that is primarily delivered to groups of high school students in school auditoriums, gymnasiums or other local venues. A national Canadian version of the program was produced by SMARTRISK, a national (Canadian) charitable organization, dedicated to preventing injuries and saving lives. Since the inception of the show, over 10 years ago, more than 1 million youth in Canada, the United States, the United Kingdom, continental Europe and Bermuda have been exposed to the program.

The program features a standard audio-visual presentation that emphasizes SMARTRISK's five injury prevention messages (i.e., "Buckle Up", "Look First", "Wear the Gear", "Get Trained" and "Drive Sober") and introduces SMARTRISK's concept of the "Stupid Line." Following the best principals of social marketing (Witte, Meyer, \& Martell, 2001; Andreasen, 1995; Kotler, Roberto, \& Lee, 2002), the audio-visual presentation has been specifically designed to appeal to youth and includes a fast moving series of images and loud music reminiscent of a music video. The program also features a verbal presentation that is delivered by a highly credible young adult injury survivor who tells their personal story of surviving injury.

The injury survivor segment emphasizes the importance of taking 'smart risks.' This segment is important because it increases the personal relevance of injury prevention for participants (e.g., injuries can happen to me) and increases the emotional impact of the presentation without resorting to 'scaring the participants straight.' Audience members are also given a question and answer session with the injury survivor in order to further address any questions or concerns that they have about injury prevention related issues. (See Figure 1 for the program logic model for the SMARTRISK Heroes Program). 
Figure 1.

SMARTRISK Heroes Program Logic Model

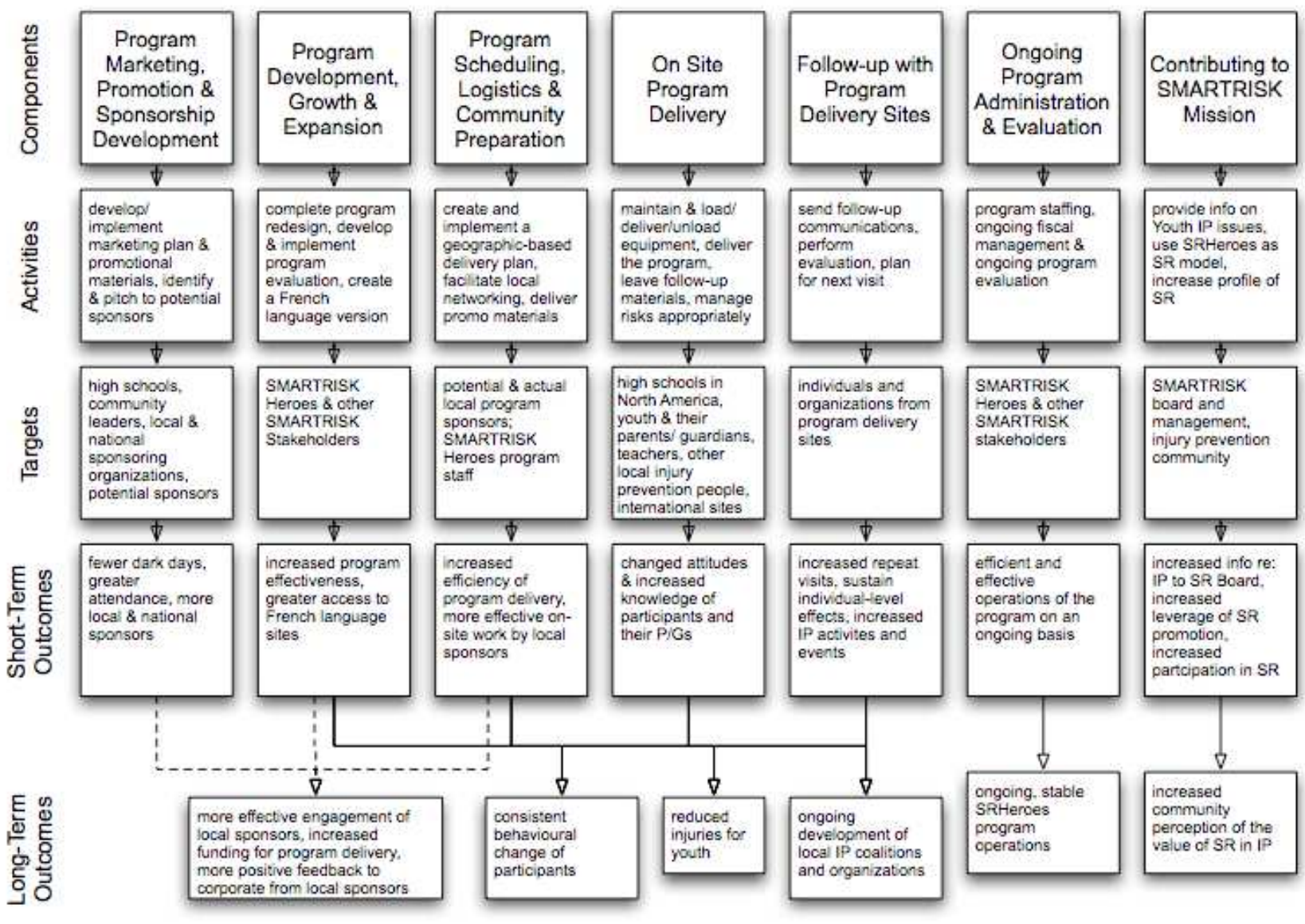

Theoretical Bases of the SMARTRISK Heroes Program

The program logic of SMARTRISK Heroes is consistent with Protection Motivation Theory (PMT) (Rogers, 1975; Rogers \& Prentice-Dunn, 1997) and the related work that integrated PMT with the transtheoretical model of stages of change (Prochaska \& DiClemente, 1983; Prochaska, Norcross \& DiClemente, 1994; Kidd, Reed, Weaver, Westneat \& Rayens, 2003).

According to PMT (Rogers \& Prentice-Dunn, 1997), an individual's likelihood of adopting a suggested health behavior is based upon four factors:

1) the perceived severity of the threat

2) the perceived vulnerability of the threat if no protective behavior is adopted

3) the efficacy of the recommended preventive behavior

4) The perceived ability to perform the recommended behavior.

The PMT also indicates that behavior is a function of two appraisal processes: threat appraisal and coping appraisal. In the threat appraisal process, the individual evaluates the maladaptive response, which may be a current behavior or one that could be started (e.g., abusing alcohol). The threat appraisal factors that increase the probability of maladaptive responses include intrinsic rewards (e.g., physical and psychological pleasure), and extrinsic rewards (e.g., peer 
approval). The threat appraisal factors that decrease the likelihood of the maladaptive response are the severity of the threat (in terms of physical, psychological, social, and economic harm) and the perceived susceptibility to the threat. Fear can also indirectly affect the appraisal of the severity of the danger.

The coping appraisal process evaluates one's ability to cope with and avert the threatened danger. The coping appraisal factors that increase the probability of the adaptive response (adoption of recommended behavior) are the individual's belief that the suggested coping response is effective and that he or she is capable of performing the suggested behavior. Coping appraisal is the combination of these appraisals of response efficacy and self-efficacy, minus any physical and psychological costs of adopting the recommended preventive behavior (Rogers \& Prentice-Dunn, 1997). A recent meta-analysis concluded that while all PMT variables were significantly correlated with intention in the predicted direction, self-efficacy was shown to have the strongest impact on intention of all of the PMT variables, and coping-appraisal components of the model had stronger associations with intention than did the threat-appraisal components (Milne, Sheehan \& Orbell, 2000).

The SMARTRISK Heroes Program addresses threat appraisal by promoting knowledge that unintentional injury is the most serious threat to the health of youth and that it can have extremely serious consequences including permanent disability or death. The program addresses coping appraisal by offering five courses of action (i.e., "Buckle Up," "Look First," "Wear the Gear," "Get Trained," and "Drive Sober") that youth can implement in order to reduce the likelihood that they are unintentionally injured or killed. The strategies are presented using a positive messaging approach with role models that are attractive to youth and in a manner that focuses on the fact that the benefits to action outweigh any barriers that might exist. The central message of the show, that a hero is anyone who takes action to save a life, even their own, further emphasizes positive coping appraisal, through increasing feelings of self-efficacy.

The transtheoretical model (TTM) was developed by Prochaska and colleagues (Prochaska \& DiClemente, 1983; Prochaska et al., 1994) and suggests that individuals progress through six stages when they change their behaviours:

1) pre-contemplation stage in which the individual either does not believe he or she has the problem or resists change

2) contemplation stage in which the individual acknowledges the problem but is not yet ready to change behaviour

3) preparation stage in which the individual makes plans to take action within a definite period of time

4) action stage in which the individual begins to actively modify his or her behaviour

5) maintenance stage in which the individual reinforces his or her actions and continues to resist temptation

6) termination stage in which the individual terminates action when it is clear that the problem behaviour will not recur. 
Block, Keller and Punam (1998) integrated PMT with the transtheoretical model of stages of behavioural change. Their empirical test of the integration of these two theories found that increasing perceptions of vulnerability led to greater intentions to comply with recommended behaviours amongst those in pre-contemplation stage. As well, increasing perceptions of severity of threat led to greater intentions to adopt suggested behaviour amongst those in contemplation stage, and increasing perceptions of response efficacy and self-efficacy led to greater behavioural intentions for those in the action stage.

The SMARTRISK Heroes Program attempts to increase perceptions of vulnerability to injury. The focus on the prevalence of unintentional injury for young people, the presentations of vignettes that describe how ordinary youth were permanently disabled by ordinary events and the live presentation by a youthful "injury survivor" serve to motivate those in the pre-contemplation and contemplation phase to want to take action. As previously noted, the presentation of the five injury prevention strategies is designed to elicit strong response-efficacy and self-efficacy for those in the action stage.

It should be noted that some research suggests that there is little evidence supporting the use of TTM to tailor interventions to individuals' action readiness state (Sutton, 1996; Weinstein, Rothman, \& Sutton, 1998). This led Abraham, Norman and Connor (2002) to conclude that programs need not be precisely targeted in terms of audience preparedness for change as this would be extremely costly. SMARTRISK has found the cost to be worthwhile, and as injury is a largely underappreciated public health issue, has focused much of the effort in SMARTRISK Heroes toward those in the pre-contemplation and contemplation stages.

\section{Evaluation History}

Notwithstanding unsubstantiated claims to the contrary (Pless, 2002a, 2002b), throughout its history, SMARTRISK Heroes has been evaluated on numerous occasions including: Leeds, Grenville \& Lanark District Health Unit (1995); SMARTRISK (1996); Smaller World Communications (1999); Green \& Camidge (2001); New Brunswick (2003); Shea, Groff \& Conn (2003); Groff, Shea, Ghadiali \& Conn (2003); and Groff, Shea \& Conn (2005a, 2005b).

At the 2003 Canadian Injury Prevention and Safety Promotion Conference, a poster was presented that described the program logic model and the comprehensive evaluation plan for the SMARTRISK Heroes Program (Shea, Groff, Conn, 2003) based on the principles of utilization-focused evaluation (Patton, 1997).

In addition, a second poster was presented at the same conference (Groff, Shea, Ghadiali \& Conn, 2003), that described the surveys used to evaluate the effects of the SMARTRISK Heroes Program on high school participants and presented preliminary evaluation findings.

Groff et al. (2003) reported that following participation in SMARTRISK Heroes, Canadian high school students showed statistically significant gains in injury prevention knowledge in several important areas. First, there was a significant increase in the proportion of participants who knew that injury was the leading cause of death for Canadians in their age group. In addition, on the post-surveys a significantly greater proportion of the program participants were able to correctly identify the meaning of the "Buckle Up" and "Drive Sober" injury prevention messages promoted by the SMARTRISK Heroes Program. SMARTRISK defines these concepts in much broader terms than other injury prevention organizations in the script for the program.

When behavioral intentions reported on the post-surveys were compared to behaviors reported on the pre-surveys, they showed significant increases in the frequency of four behaviors that 
would decrease the likelihood of their being unintentionally injured or killed. These behaviors were:

- wearing a helmet while riding a bicycle;

- wearing protective gear while playing sports;

- participating in training before attempting a new sport or recreational activity;

- wearing protective equipment while at work.

Information on the more recent participant evaluation processes being used with the SMARTRISK Heroes Program as well as some preliminary results in this area have been presented on the SMARTRISK Navigator website (SMARTRISK 2004, 2005). In addition, some of the results discussed in this article were presented at the Ontario Injury Prevention Conference (Groff, Shea \& Conn, 2005b).

Groff et al. (2005b) reported the results from participant evaluations performed in Northern England and Cornwall, Ontario in 2004. Some of these results were also presented in a SMARTRISK Navigator (Internet) article (SMARTRISK, 2005).

The evaluation findings from Northern England were based upon 214 matched surveys in which the same students completed pre-surveys prior to the start of the SMARTRISK Heroes Program, post-surveys immediately following the program and follow-up surveys, three months after they had experienced the program. The findings from Cornwall are based upon 113 matched surveys of the three types.

Table 1 presents the percentage of students from the combined UK samples who responded correctly to each of the seven knowledge questions on each of the three surveys. As can be seen, for five of the seven questions, significantly more students answered them correctly at post-test than had on the pre-test. Equally important, on each of these five items the percentage getting the correct response remained significantly higher at follow-up than at pretest, though for one of them there was a significant decline from post-test to follow-up-test. The remaining two knowledge items showed a significant increase in correct responses from pre-test to follow-up-test, perhaps implying that informal and formal discussion in the three months following the show had served to reinforce the information presented.

Table 1.

Percentage of Correct Responses on Pre-, Post- and Follow-up Surveys for Each Knowledge Item

\begin{tabular}{|c|c|c|c|c|c|}
\hline Item & Pre & $*$ & Post & $*$ & Follow-up \\
\hline What is the leading cause of death of UK youth aged $11-19 ?$ & $25.0 \%$ & $<$ & $59.9 \%$ & $>$ & $48.3 \% * *$ \\
\hline According to SMARTRISK, the "Stupid Line" is... & $73.5 \%$ & $<$ & $82.0 \%$ & $=$ & $87.0 \%$ \\
\hline According to SMARTRISK, to "Drive Sober" means.. & $19.0 \%$ & $<$ & $40.7 \%$ & $=$ & $35.1 \%$ \\
\hline According to SMARTRISK, to "Wear the Gear" means... & $79.6 \%$ & $=$ & $79.8 \%$ & $<$ & $88.5 \% * *$ \\
\hline According to SMARTRISK, to "Look First" means... & $17.6 \%$ & $<$ & $30.6 \%$ & $=$ & $26.8 \%$ \\
\hline According to SMARTRISK, to "Buckle Up" means... & $25.8 \%$ & $<$ & $54.6 \%$ & $=$ & $56.8 \%$ \\
\hline According to SMARTRISK, to "Get Trained" means... & $73.0 \%$ & $=$ & $71.2 \%$ & $<$ & $85.2 \% * *$ \\
\hline
\end{tabular}

*Significant $(p \leq 0.05)$ increases between the proportion correct in from one column to the column to its immediate right are marked with an " $<$ ". Significant decreases $(p \leq 0.05)$ are marked with an " $>$ ". Boldface symbols indicate differences significant at $(p \leq 0.001)$. Non-significant differences are marked with an $=$ sign. All differences tested with McNemar's test.

** Significant $(\mathrm{p} \leq 0.05)$ increases between the proportion correct at Pre-test and that at Follow-up, notwithstanding the relationship between Pre and Post. Boldface symbols indicate differences significant at $(p \leq 0.001)$. All differences tested with McNemar's test. 
Students from both samples also demonstrated significant changes in their attitudes related to personal vulnerability and the perceived preventability of injuries that were retained at followup (See Table 2). Respondents were asked a number of questions designed to capture their attitudes about risk taking, including an assessment of their own personal propensity to take risks. Students indicated their agreement with six statements using a five-point Likert-type scale. For the first question this scale ranged from "Never Take Risks" to "Always Take Risks." For the remaining five attitude questions, the scales ranged from "Strongly Disagree" to "Strongly Agree."

Table 2.

Mean Responses (Standard Deviations) on Pre-, Post- and Follow-up Surveys for Each Attitude Item

\begin{tabular}{|c|c|c|c|c|c|}
\hline Item & Pre & $*$ & Post & $*$ & Follow-up \\
\hline $\begin{array}{l}\text { How would you rate yourself in terms of your overall } \\
\text { tendency toward risk taking? }\end{array}$ & $\begin{array}{r}2.74 \\
(0.853)\end{array}$ & $=$ & $\begin{array}{r}2.79 \\
(0.947)\end{array}$ & $=$ & $\begin{array}{r}2.83 \\
(0.941)\end{array}$ \\
\hline $\begin{array}{l}\text { It is my life and if I take risks, I am only endangering } \\
\text { myself. }\end{array}$ & $\begin{array}{r}3.15 \\
(1.186) \\
\end{array}$ & $>$ & $\begin{array}{r}2.82 \\
(1.231) \\
\end{array}$ & $<$ & $\begin{array}{r}3.02 * * \\
(1.253) \\
\end{array}$ \\
\hline $\begin{array}{l}\text { I can rely upon my parents/ guardians and teachers to } \\
\text { understand the risks in a specific situation. }\end{array}$ & $\begin{array}{r}3.44 \\
(1.050)\end{array}$ & $>$ & $\begin{array}{r}3.20 \\
(1.096)\end{array}$ & $=$ & $\begin{array}{r}3.14 \\
(1.083)\end{array}$ \\
\hline $\begin{array}{l}\text { Life is about taking risks that you face in everyday life and } \\
\text { choosing how to manage them. }\end{array}$ & $\begin{array}{r}3.81 \\
(0.837) \\
\end{array}$ & $=$ & $\begin{array}{r}3.90 \\
(0.892) \\
\end{array}$ & $=$ & $\begin{array}{r}3.80 \\
(0.938) \\
\end{array}$ \\
\hline $\begin{array}{l}\text { I can make choices about many of the risks that might lead } \\
\text { to my injury or death. }\end{array}$ & $\begin{array}{r}3.65 \\
(1.153)\end{array}$ & $<$ & $\begin{array}{r}3.92 \\
(0.972)\end{array}$ & $>$ & $\begin{array}{r}3.69 \\
(0.998)\end{array}$ \\
\hline $\begin{array}{l}\text { If I am injured while riding as a passenger with a driver who } \\
\text { is impaired, it is my responsibility because I chose to take } \\
\text { the ride. }\end{array}$ & $\begin{array}{r}2.21 \\
(1.166)\end{array}$ & $<$ & $\begin{array}{r}3.72 \\
(1.056)\end{array}$ & $>$ & $\begin{array}{l}3.56 * * \\
(1.055)\end{array}$ \\
\hline
\end{tabular}

*Significant $(p \leq 0.05)$ increases between the level of agreement from one column to the column to its immediate right are marked with an " $<$ ". Significant decreases $(p \leq 0.05)$ are marked with an " $>$ ". Boldface symbols indicate differences significant at $(p \leq 0.001)$. Non-significant differences are marked with an " $="$ sign. All differences tested with Wilcoxon Signed-Rank Test.

** Significant $(p \leq 0.05)$ differences between the level of agreement at Pre-test and that at follow-up, notwithstanding the relationship between pre and post. Boldface symbols indicate differences significant at ( $p \leq$ 0.001). All differences tested with Wilcoxon Signed-Rank Test.

Note that although means and standard deviations are presented for ease of interpretation, the conservative decision to conduct inferential analyses using non-parametric tests was made, and thus conclusion of which differences are significant are actually based on mean ranks, rather than means.

Finally, students from both groups also showed significant changes in their intent to perform or not perform a number of behaviors that would reduce their likelihood of experiencing an unintentional injury or death (e.g., wearing a bicycle helmet, driving a vehicle while distracted, riding with a driver who had been drinking alcohol or using drugs). At follow-up, some of these "good intentions" had not resulted in actual behavior changes. However, on the three-month follow-up, the Cornwall students did show increased wearing of bicycle helmets (when compared to the period three months before the SMARTRISK Heroes show) and the students from Northern England reported that they had significantly increased their actual frequencies of participation in training before attempting a new sports activity and wearing appropriate protective gear while at work (Table 3). 
Respondents were provided a number of scenarios and were asked to report on the frequency with which they performed these behaviors in the last three months in the pre-survey. In the post-survey, respondents were asked to report on their intended behavior. Finally, at follow-up, students were again asked to report on the frequency with which they performed these behaviors. Students responded to each statement using a five-point, Likert-type scale ranging from "Never" to "All the Time."

Table 3.

Mean Responses (Standard Deviations) on Pre-, Post- and Follow-up Surveys for Each Behavior Item

\begin{tabular}{|c|c|c|c|c|c|}
\hline Item & Pre & $*$ & Post & $*$ & Follow-up \\
\hline $\begin{array}{l}\text { I wore/will wear my seatbelt while riding as a passenger in a } \\
\text { motor vehicle }\end{array}$ & $\begin{array}{r}4.51 \\
(0.861) \\
\end{array}$ & $=$ & $\begin{array}{r}4.43 \\
(1.027) \\
\end{array}$ & $=$ & $\begin{array}{r}4.35 \\
(1.065) \\
\end{array}$ \\
\hline $\begin{array}{l}\text { I wore/will wear a cycle helmet with the strap done up while } \\
\text { riding a bicycle }\end{array}$ & $\begin{array}{r}1.41 \\
(1.015)\end{array}$ & $<$ & $\begin{array}{r}2.61 \\
(1.601) \\
\end{array}$ & $>$ & $\begin{array}{r}1.52 \\
(1.011)\end{array}$ \\
\hline $\begin{array}{l}\text { I tripped or stumbled / will trip or stumble on stairs because I } \\
\text { was not paying attention }\end{array}$ & $\begin{array}{r}2.06 \\
(0.923) \\
\end{array}$ & $<$ & $\begin{array}{r}2.26 \\
(1.190) \\
\end{array}$ & $=$ & $\begin{array}{r}2.26 \\
(0.993) \\
\end{array}$ \\
\hline $\begin{array}{l}\text { tective gear (e.g., elbow and wrist } \\
\text { playing sports (e.g., skateboarding, } \\
\text {, hockey) }\end{array}$ & $\begin{array}{r}1.99 \\
(1.352)\end{array}$ & $<$ & $\begin{array}{r}3.33 \\
(1.399)\end{array}$ & $>$ & $\begin{array}{r}2.28 \\
(1.417)\end{array}$ \\
\hline $\begin{array}{l}\text { e (e.g., car, mot } \\
\text { eing driven by sc } \\
\text { gs }\end{array}$ & $\begin{array}{r}1.21 \\
(0.699)\end{array}$ & $=$ & $\begin{array}{r}1.24 \\
(0.736)\end{array}$ & $=$ & $\begin{array}{r}1.23 \\
(0.645)\end{array}$ \\
\hline $\begin{array}{l}\text { pated / will participate in training before attempting } \\
\text { orts activities (e.g., skiing, snow boarding, rock } \\
\text { g, driving a snow machine) }\end{array}$ & $\begin{array}{r}2.97 \\
(1.513)\end{array}$ & $<$ & $\begin{array}{r}4.00 \\
(1.156)\end{array}$ & $>$ & $\begin{array}{l}3.48 * * \\
(1.380)\end{array}$ \\
\hline n /will have a plan on ho & $\begin{array}{r}3.87 \\
(1.311)\end{array}$ & $=$ & $\begin{array}{r}4.03 \\
(1.187)\end{array}$ & $=$ & $\begin{array}{r}3.96 \\
(1.245)\end{array}$ \\
\hline a job without being & $\begin{array}{r}1.55 \\
(1.163) \\
\end{array}$ & $=$ & $\begin{array}{r}1.69 \\
(1.099) \\
\end{array}$ & $>$ & $\begin{array}{r}1.50 \\
(1.084) \\
\end{array}$ \\
\hline $\begin{array}{l}\text { I drove / will drive a vehicle (e.g., bike, car, snow machine) } \\
\text { while being distracted by something (e.g., cell phone, talking } \\
\text { with a friend) }\end{array}$ & $\begin{array}{r}1.89 \\
(1.230)\end{array}$ & $=$ & $\begin{array}{r}1.61 \\
(0.895)\end{array}$ & $=$ & $\begin{array}{r}1.54 \\
(0.979)\end{array}$ \\
\hline $\begin{array}{l}\text { When working (e.g., on the job, doing chore } \\
\text { wear protective gear (e.g., safety goggles, }\end{array}$ & $\begin{array}{r}2.05 \\
(1.415) \\
\end{array}$ & $<$ & $\begin{array}{r}3.63 \\
(1.436) \\
\end{array}$ & $>$ & $\begin{array}{l}2.67 * * \\
(1.648)\end{array}$ \\
\hline
\end{tabular}

*Significant $(p \leq 0.05)$ increases between the frequency reported from one column to the column to its immediate right are marked with an "<". Significant decreases $(p \leq 0.05)$ are marked with an " $>$ ". Boldface symbols indicate differences significant at $(p \leq 0.001)$. Non-significant differences are marked with an " $="$ sign. All differences tested with Wilcoxon Signed-Rank Test.

** Significant $(p \leq 0.05)$ differences between the frequencies reported at pre-test and that at follow-up, notwithstanding the relationship between pre and post. Boldface symbols indicate differences significant at $(\mathrm{p} \leq$ 0.001). All differences tested with Wilcoxon Signed-Rank Test.

Note that although means and standard deviations are presented for ease of interpretation, the conservative decision to conduct inferential analyses using non-parametric tests was made, and thus conclusion of which differences are significant are actually based on mean ranks, rather than means.

As noted in Table 3 above, students indicated intent to change their behavior on five of the 10 questions asked at post-test, when compared to their actual reported behavior for the three months prior to the show. For two of these behaviors (getting trained prior to new sports activities, and wearing the gear while on the job), the frequency was significantly different from 
pre-test levels at follow-up-test, though not at the level anticipated by the students, immediately following the show. For two other behaviors (wearing a cycle helmet, and wearing other sports gear), their reported frequency had reverted to pre-test levels after three months, despite the intentions reported after the show. Finally, for one of the behaviors, the reported frequency at follow-up, matched their intended frequency immediately after the show, unfortunately, for this behavior (Tripping and falling on stairs due to inattention) the change was in the non-desired direction, perhaps reflecting an increased awareness of tripping hazards rather than an actual intention to fall more frequently which the students subsequently followed through with.

\section{Conclusion}

SMARTRISK Heroes is helping students to understand that it's up to them - not their parents or their friends - to prevent themselves from being injured. By taking adolescents from the precontemplation to the action stage, with messages specifically designed to elicit positive threat and coping appraisals, SMARTRISK Heroes is able to create a "teachable moment" where young people learn that they are at risk, and that it is within their power to do something about it.

For further information on SMARTRISK Heroes visit the SMARTRISK Navigator Web Site (http://www.smartrisk.ca/) and select SMARTRISK Heroes, under the Youth tab.

\section{References}

Abraham, C., Norman, P., \& Conner, M. (2002). Towards a Psychology of Health-Related Behaviour Change. In P. Norman, M. Abraham \& M. Conners (Eds.), Understanding and Changing Health Behavior: from Beliefs to Self-Regulation. Amsterdam: Hardwood Academic Publishers.

Andreasen, A. R. (1995). Marketing Social Change: Changing Behavior to Promote Health, Social Development, and the Environment. San Francisco: Jossey-Bass (A Wiley Imprint)

Block, G. L., \& Keller, A., Punam. (1998). Beyond Protection Motivation: An Integrative Theory of Health Appeals. Journal Of Applied Social Psychology, 28((17)), (1584-1608).

Centers for Disease Control and Prevention (CDC). (2005a). Ten Leading Causes of Death by Age Group, 2002. URL: ftp://ftp.cdc.gov/pub/ncipc/10LC-2002/PDF/10lc-2002.pdf

Centers for Disease Control and Prevention (CDC). (2005b). Ten Leading Causes of Injury Death: Highlighting Unintentional Injury. URL: ftp://ftp.cdc.gov/pub/ncipc/10LC2001/PDF/10lc-unintentional.pdf

Green, J. \& Camidge, D. (2001). Evaluation of the SMARTRISK Heroes Show. Leeds Metropolitan University, Leeds, England.

Groff, P.; Shea, M.; Ghadiali, J. \& Conn, R. (2003). Developing and Implementing Participant Evaluation Surveys for SMARTRISK Heroes: Lessons Learned and Preliminary Findings. Poster presented at the Canadian Injury Prevention and Safety Promotion Conference, Ottawa, Ontario, October 2003. 
Groff, P.; Shea, M. \& Conn, R. (2005a). SMARTRISK Heroes Program: Summary of Past Evaluations. SMARTRISK Foundation, Toronto, Ontario, Canada (posted on the Internet at www.smartrisk.ca).

Groff, P.; Shea, M. \& Conn, R. (2005b). Evaluating the Longer-Term Effects of the SMARTRISK Heroes program Using Follow-up Surveys with Samples of Student Populations. Paper presented at the Ontario Injury Prevention Conference, London, Ontario, March 22 ${ }^{\text {nd }}, 2005$.

Kidd, P.; Reed, D.; Weaver, L.; Westneat, S. \& Rayens, M. K. (2003). The Transtheoretical Model of Change in Adolescent: Implications for Injury Prevention. Journal of Safety Research, 34, 281-288.

Kotler, P., Roberto, N., and Lee, N. (2002). Social Marketing: Improving the Quality of Life, $2^{\text {nd }}$ ed. Thousand Oaks, CA: Sage.

Leeds, Grenville and Lanark District Health Unit (1995). Evaluation of Injury Prevention Strategies: Heroes. LGLDHU Department of Professional Resources \& Department of Community Health Services, Brockville, ON.

Milne, S., Sheeran, P., \& Orbell, S. (2000). Prediction and Intervention in Health-Related Behavior: A Meta-Analytic Review of Protection Motivation Theory. Journal Of Applied Social Psychology, 3(1), (106-143).

New Brunswick Safety Council \& Workers' Health and Safety Compensation Commission (2003). New Brunswick Heroes Tour: Evaluation Results. Fredericton, NB.

Patton, M. Q. (1997). Utilization-Focused Evaluation: The New Century Text (Third Edition). Sage Publications, Thousand Oaks: CA.

Pless, B. (2002a). Taking Risks with Injury Prevention. Canadian Medical Association Journal. $167,7(767-768)$.

Pless, B. (2002b). From the editor's desk. Injury Prevention, 8, (173-174).

Prochaska, J. O., \& DiClemente, C. C. (1983). Stages and Processes of Self-Change of Smoking: Toward an Integrative Model of Change. Journal of Consulting and Clinical Psychology, 51, 390395.

Prochaska, J. O., Norcross, J. C., \& DiClemente, C. C. (1994). Changing for Good. New York: William Morrow.

Rogers, R. W. (1975). A Protection Motivation Theory of Fear Appeals and Attitude Change. The Journal of Psychology, 91, 93-114.

Rogers, W. R., \& Prentice-Dunn, S. (1997). Protection Motivation Theory. In S. D. Gochman (Ed.), Handbook of Health Behavior Research I: Personal and Social Determinants (pp. (113132)). New York: Plenum Press. 
Shea M. P.; Groff, P. \& Conn, R. (2003). Lessons Learned During the Design and Implementation of an Evaluation Framework for the SMARTRISK Heroes Program. Poster presented at the Canadian Injury Prevention and Safety Promotion Conference, Ottawa, Ontario, October 2003.

Smaller World Communications (1999). An Evaluation of Heroes. Richmond Hill, ON.

SMARTRISK (1996). An Evaluation of the HEROES Program. Toronto, Canada: SMARTRISK Foundation.

SMARTRISK (2000). SMARTRISK Heroes Program Description. Toronto, Canada: SMARTRISK Foundation.

SMARTRISK (2004). Preventing injury in their hands, students learn. SMARTRISK Navigator article posted 2004/09/13 at www.smartrisk.ca.

SMARTRISK (2005). SMARTRISK Heroes makes lasting impression. SMARTRISK Navigator article posted 2005/04/07 at www.smartrisk.ca.

SMARTRISK UK (2005). SMARTRISK UK Heroes Program Evaluation Plan. Leeds, England: SMARTRISK UK.

Statistics Canada (2005). Canadian Vital Statistics, Death Database. Causes of death. Chapter XX: External causes of morbidity and mortality (V01-Y89), by age group and sex. Ottawa: Statistics Canada; 2002. Cat. No: 84-208-XIE.

Sutton, S. R. (1996). Can 'Stages of Change' Provide Guidance in the Treatment of Addictions? A Critical Examination of Prochaska and DiClemente's model. In G. Edwards \& C. Dare (Eds.), Psychotherapy, Psychological Treatments and the Addictions. Cambridge: Cambridge University Press.

Weinstein, N. D., Rothman, A. J., \& Sutton, S. R. (1998). Stage Theories of Health Behavior: Conceptual and Methodological Issues. Health Psychology, 17, 290-299.

Witte, K., Meyer, G., and Martell, D. (2001). Effective Health Risk Messages: A Step-by-Step Guide. Thousand Oaks, CA: Sage.

(c) Copyright of Journal of Youth Development Bridging Research and Practice. Content may not be copied or emailed to multiple sites or posted to a listserv without copyright holder's express written permission. Contact Editor at: patricia.dawson@oregonstate.edu for details. However, users may print, download or email articles for individual use.

ISSN 2325-4009 (Print); ISSN 2325-4017 (Online) 